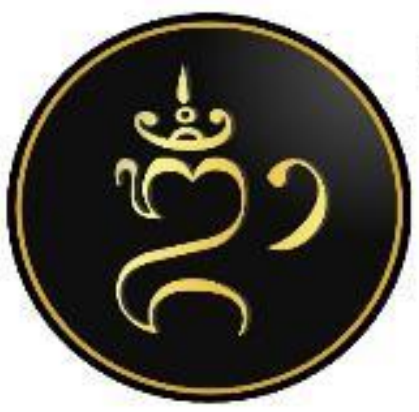

E-ISSN: $2722-8576$

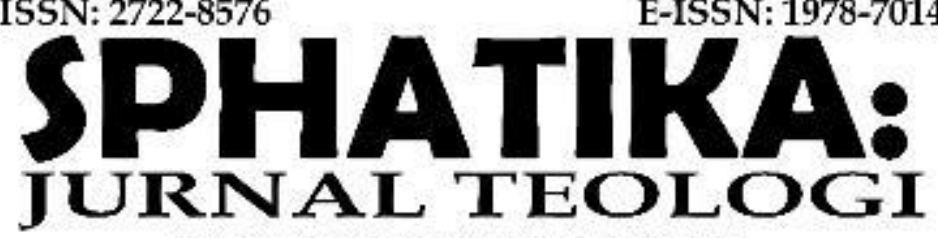

UNIVERSITAS HINDU NEGERI

I GUSTI BAGUS SUGRIWA DENPASAR

VOLUNE 12 NOMOR 1, MARET 2021

\title{
PENGENALAN SENI SUARA DHARMAGĪTĀ “SEKAR AGUNG" BERBASIS MULTIMEDIA INTERAKTIF
}

\author{
Putu Eka Sura Adnyana1, I Made Ade Prayoga ${ }^{2}$ \\ Aliansi Pemuda Hindu Bali'1, Dinas Komunikasi Infomatika dan Statistik Kota \\ Denpasar $^{2}$ \\ ekasuraadnyana@gmail.com ${ }^{1}$
}

Keywords:

art sound;

multimedia

interactive; sekar

agung
Kata kunci:

multimedia

interaktif; sekar

agung; seni suara
Abstract (Justify, Italic and Bold, book antiqua 11)

The Interactive Multimedia-based Sekar Agung Art Sound Introduction is the newly cutting edge innovation in order to introduce Balinese culture especially Sekar Agung which is particularly a part of Dharmagita - Dharmagita is a sacred verse of Hindus. Furthermore, in this modern era, Balinese Hindus mostly unable to acknowledge the true meaning of that relic lullaby such as what is Sekar Agung, what is it containing, what else is including in Sekar Agung. The Interactive Multimedia-based Sekar Agung Introduction was incorporating the MDLC Multimedia Development Life Cycle method with Adobe Flash as it main software and ActionScript 3.0 as it programming operation. The final result of this research was a form of Interactive Multimedia application which contained information, course and material, audio and video related to Dharmagita, Sekar Agung and also a Quizzes to evaluate the user's knowledge about Sekar Agung. This application could be utilized as Learning Reference and an Introduction of Sekar Agung which helps it become understandable, more innovative and interactive.

Abstrak (rata kanan kiri, cetak miring dan tebal, book antiqua 11)

Pengenalan Seni Suara Sekar Agung Berbasis Multimedia Interaktif merupakan inovasi baru dalam cara untuk memperkenalkan budaya Bali khusunya sekar agung yang merupakan salah satu bagian dari dharmagita. Dharmagita adalah nyayian suci keagamaan khususnya agama Hindu. Pada era modern ini masyarakat hindu Bali belum memahami betul apa itu sekar agung apa saja bagian dari sekar agung. Aplikasi pengenalan seni suara sekar agung berbasis mutimedia interaktif ini menggunakan metode MDLC (Multimedia Development Life Cycle), adobe flash sebagai software dan actionscript 3.0 sebagai 
bahasa pemrogramanya. Hasil akhir dari penelitian ini berupa aplikasi multimedia interaktif yang berisikan informasi, materi, audio dan video terkait dharmagita, sekar agung, dan berisikan kuis untuk mengevaluasi pengetahuan tentang sekar agung. Aplikasi ini dapat dijadikan referensi pembelajaran serta untuk memperkenalkan sekar agung dengan lebih praktis, inovatif dan interaktif.

\section{PENDAHULUAN}

Dharmagita adalah nyanyian keagamaan umat Hindu biasa digunakan mengiringi berbagai kegiatan upacara keagamaan, khususnya yang berhubungan dengan ritual/yadnya. Penggunaan Dharmagita dalam kegiatan tersebut sangat dibutuhkan karena irama lagunya memiliki berbagai jenis variasi yang sangat membantu dalam menciptakan suasana hening, hidmat/khusuk yang dipancari getaran kesucian sesuai dengan jenis yadnya yang dilakukan. Di samping itu, dilihat dari tema syair-syairnya, umumnya mengandung ajaran agama, susila, tuntunan hidup yang baik serta lukisan kebesaran Hyang Widhi dalam berbagai prabhawa-Nya yang dipuja oleh umat Hindu. Dharmagita ini di bagi menjadi empat bagian yaitu sekar alit, sekar madya, dan sekar agung.

Aplikasi berbasis multimedia interaktif ini mengambil bagian Dharmagita yaitu pada bagian Sekar Agung. Sekar Agung adalah bagian ketiga dari Dharmagita, setelah sekar alit dan sekar madya. Sekar Agung terdiri atas tiga bagian yaitu Kakawin, Palawakya dan Sloka (Disbud, 2011). Kakawin adalah puisi Jawa Kuno yang dinyanyikan berdasarkan guru-laghu, yang dimaksud guru lagu adalah adanya suara berat dan panjang atau ringan dan lambat dalam tembang kakawin. Selain itu ada pula aturan kakawin yaitu "Wreta" yaitu adanya suku kata kecap yang membentuk empat baris atau tiga baris menjadi satu bait atau "pada" dalam kekawin. Palawakya adalah salah satu jenis teks keagamaan yang biasanya dibacakan dengan irama dan intonasi khas dalam hubungan yadnya. Berbeda dengan sloka, palawakya ini berbentuk prosa berbahasa Jawa Kuna dan muncul terkadang bait sloka/sruti berbahasa Sanskerta pada teks prosa, sedangkan Sloka ditembangkan dengan irama sruti dan aturan guru-laghu dalam proses penembangannya. Sloka biasanya terdiri atas empat baris dalam satu bait dengan jumlah suku kata biasanya sama dan berbahasa Sanskerta. Sloka adalah kumpulan mantramantra di dalam agama Hindu yang sering digunakan di dalam upacara keagamaan.

Beberapa tahun terakhir ini apalagi banyaknya pengaruh luar yang masuk ke-Bali mengakibatkan banyak sekali pergeseran budaya yang terjadi, dan kecenderungan 
minat baca masyarakat terhadap buku mengenai sekar agung sangat sedikit sehingga saat ini orang Bali khususnya yang beragama Hindu banyak yang tidak mengetahui fungsi dari Sekar Agung ini dalam peranannya sebagai salah satu sarana pendukung dalam kegiatan kesenian maupun upacara keagamaan agama Hindu. Maka dari itu perlu adanya suatu media berbasis teknologi yang dapat digunakan untuk lebih memahami dan mengetahui fungsi Sekar Agung.

Berdasarkan penjelasan diatas akan dibuat sebuah multimedia interaktif yang sesuai dengan teknologi yang sedang berkembang saat ini. Maka dari itu adanya media yang dapat digunakan untuk mengenalkan Sekar Agung, diharapkan agar masyarakat Hindu mengetahui warisan budaya leluhur melalui artikel ilmiah yang berjudul "Pengenalan Seni Suara Sekar Agung Berbasis Multimedia Interaktif"

\section{METODE DAN TAHAPAN DASAR MULTIMEDIA INTERAKTIF}

Sumber dari aplikasi ini terdapat pada buku yang diterbitkan dari Dinas Kebudayaan Provinsi Bali, berjudul Utsawa Dharmagita. Tahapan pengumpulan data dimulai dengan menyimak teks dilanjutkan dengan teknik baca (menembangkan) teks Sekar Agung yang meliputi Kakawin, Palawakya dan Sloka dengan kombinasi teknik rekam yang dilakukan dengan cara merekam proses penembangan Sekar Agung. instrument yang digunakan adalah voice recorder, kamera (video recorder). Kemudian dilanjutkan dengan pembuatan aplikasi multimedia interaktif. Aplikasi ini memiliki struktur menu diantaranya 1) Pengenalan Dharmagita, 2) Pengenalan Sekar Agung 3) Video dan Audio tiga bagian Sekar Agung, 4) Media tanya jawab, 5) Tentang kami, Aplikasi ini bersifat offline dan online 6) Aplikasi ini hanya menyediakan informasi mengenai pengenalan Dharmagita, pengenalan Sekar Agung, Video dan Audio tiga bagian Sekar Agung, dan media tanya jawab, 7) Aplikasi ini terdapat video dan audio tiga bagian Sekar Agung, 8) Aplikasi ini dibuat menggunakan Adobe Flash CC 2015 dengan Bahasa pemrograman ActionScript 3.0,9) Aplikasi ini dibuat menggunakan computer berspesifikasi sebagai berikut:
a. Intel Core i7-4710@2.50Ghz
b. Kingston HyperX Fury Black 2x4GB DDR3 PC15000 1866mhz
c. Harddisk WD Caviar Blue 1TBx2
d. VGA Nvidia Geforce GT 840M 2Gb 
Metode yang digunakan dalam aplikasi ini adalah MDLC (Multimedia Developmen Life Cricle) yang terdiri dari; 1) Menentukan tujuan pembuatan aplikasi ini yaitu digunakan sebagai media pengenalan Seni Suara Sekar Agung agar masyarakat khususnya mahasiswa mengerti dan memahami apa itu Dharmagitha, bagian dari Dharmagitha, pengertian Sekar Agung dan bagian-bagian dari Sekar Agung, 2) Aplikasi ini digunakan untuk media pengenalan Seni Suara Sekar Agung oleh masyarakat khususnya SMP sampai SMA, 3) Deskripsi aplikasi pengenalan Seni Suara Sekar Agung ini berjalan dan di operasikan pada perangkat berbasis windows dan android.

Pada tahap ini pembuat atau pengembang proyek multimedia menjabarkan secra rinci apa yang akan dilakukan dan bagaimana proyek multimedia tersebut akan disajikan. Tahap ini meliputi penulisan naskah, pembuatan storyboard, pembuatan struktur menu, dan membuat desain yang digunakan pada aplikasi agar menarik pengguna dengan menggunakan software CorelDrawX7 dan Photoshoop. Tahap ini merupakan proses untuk mengumpulkan segala data yang dibutuhkan dalam proyek. Mengenai materi yang akan disampaikan, kemudian file-file multimedia seperti gambar, video, dan audio yang akan dimasukan dalam penyajian proyek multimedia tersebut.

Pada tahap ini proyek multimedia diproduksi. Materi-materi serta file-file multimedia yang sudah terkumpul kemudian dirangkai dan disusun sesuai desain dengan menggunakan bahasa pemrograman. Pada tahap ini digunakan software seperti, CorelDrawX7, Photoshoop, dan lainnya untuk membuat aplikasi pengenalan seni suara sekar agung berbasis multimedia interaktif.

Pada tahap ini dilakukan uji coba terhadap aplikasi multimedia yang dibuat. Uji coba dilakukan dengan menerapkan hasil dari proyek multimedia tersebut pada pengenalan. Pada tahap ini digunakan pengujian dengan menggunakan BlackBox Testing untuk menguji fungsional yang ada di dalam aplikasi apakah berjalan sesuai dengang apa yang diharapkan oleh pembuat.

Tahap penggandaan dan penyebaran hasil kepada pengguna.multimedia perlu dikemas dengan baik sesuai dengan media penyebar luasnya, apakah dengan melalui CD/DVD, download, distribusi atau diupload ke media sosial youtube, ataupun media lainnya. 


\section{PEMBAHASAN}

\section{Aplikasi Multimedia}

Perangkat lunak aplikasi (Aplication Software) adalah perangkat lunak yang digunakan untuk membantu pemakai komputer untuk melaksanakan pekerjaannya. Akan tetapi, program-program tersebut tidak ditujukan untuk menyelesaikan permasalahan dalam aplikasi tertentu yang dihadapi oleh pemakai komputer. Dari pengertian diatas, dapat disimpulkan bahwa aplikasi merupakan software/perangkat lunak yang berfungsi untuk melakukan berbagai bentuk pekerjaan atau tugas-tugas tertentu untuk meringankan pengguna dalam melakukan pekerjaannya. Multimedia adalah pemanfaatan komputer untuk membuat dan menggabungkan teks, grafik, gambar bergerak (video dan animasi) dengan menggabungkan link dan tool yang memungkinkan pemakai melakukan navigasi, berinteraksi, berkreasi, dan berkomunikasi. Dalam definisi ini terkandung empat komponen penting multimedia. Pertama, harus ada komputer yang mengkoordiasikan apa yang dilihat dan didengar, yang berinteraksi dengan pengguna. Kedua, harus ada link yang menghubungkan pengguna dengan informasi. Ketiga, harus ada alat navigasi yang memandu pengguna, menjelajah jaringan informasi yang saling terhubung. Keempat, multimedia menyediakan tempat kepada pengguna untuk mengumpulkan, memproses dan mengkomunikasikan informasi dan ide pengguna. Dari definisi diatas dapat disimpulkan aplikasi multimedia adalah aplikasi yang dirancang serta dibangun dengan menggabungkan element-element seperti document, suara, gambar, animasi serta video. Pemanfaatan dari aplikasi multimedia dapat berupa company profile, dan video untuk tutorial (Munir, 2014).

Melalui Aplikasi multimedia dengan tranformasi teknologi masa kini, maka proses pembelajaran dan pengenalan seni suara sekar agung dapat dilakukan dengan teknologi, mengikuti perkembangan jaman. Proses pembelajaran melalui teknologi sangat menarik dan memudahkan untuk generasi muda Hindu di seluruh Nusantara dan khususnya Bali.

\section{Implementasi Sistem Aplikasi}

Implementasi sistem ini berupa aplikasi pengenalan yang dibuat dengan menggunakan Adobe Flash dengan menggunakan bahasa pemrograman Actionscript 3.0. Desain aplikasi dibuat dengan menggunakan CorelDRAW X7, pengolahan video dibuat dengan menggunakan Adobe Premiere Pro CC 2015 dan pengolahan audio pada video 
menggunakan Adobe Audition Pro CC 2015. Dimulai dari Halaman splashscreen yang ditujukan pada Gambar 3.1 merupakan halaman awal ketika menjalankan aplikasi pengenalan sekar agung. Pada halaman ini user memilih tombol mulai untuk menuju ke halaman menu utama aplikasi. Adapun sebagai berikut halaman Splashscreen.

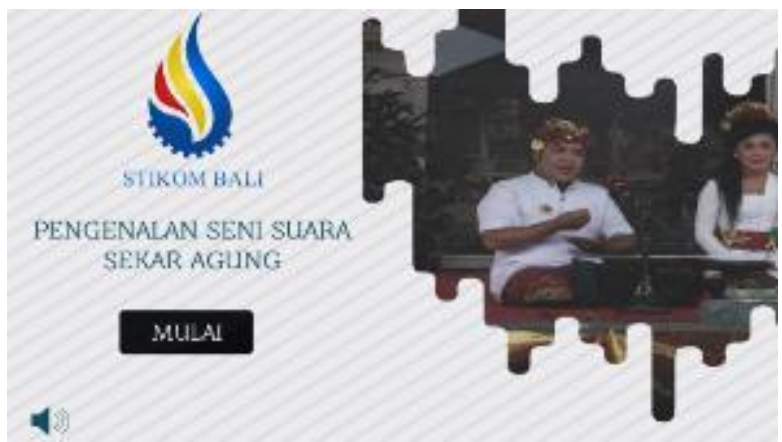

Gambar 2.1

Halaman menu utama yang ditujukan pada Gambar 2.1 merupakan halaman utama setelah user mengklik tombol mulai pada halaman splashceen. Pada halaman ini user dapat memilih menu-menu yang diinginkan.

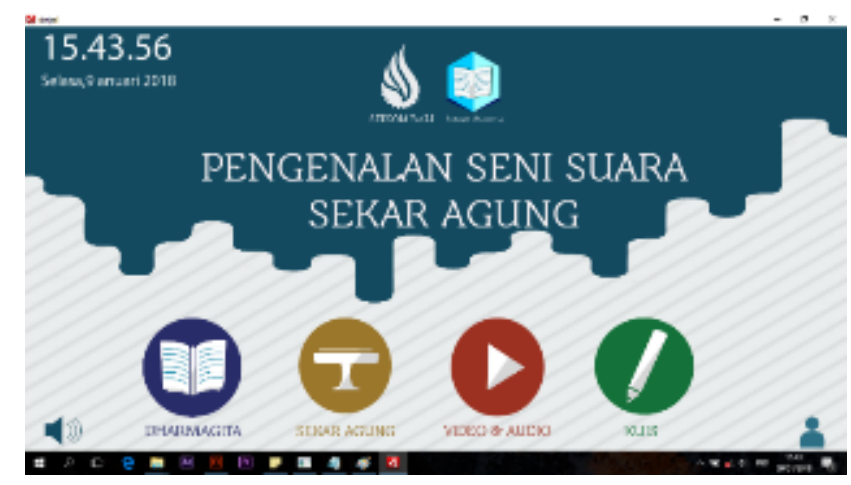

Gambar 2.2

Tampilan Dharmagita dimulai dari Halaman Dharmagita yang ditujukan pada Gambar 2.2 merupakan halaman dimana user dapat mengetahui pengertian dari dharmagita. Pada halaman ini user dapat berinteraksi dengan sistem ketika ingin mengetahui materi tentang Dharmagita dengan memilih salah satu menu yang ada di dalam aplikasi.

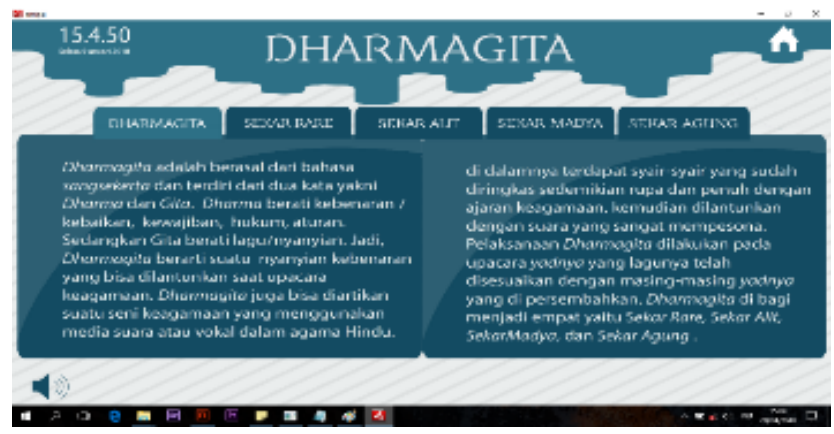

Gambar 2.3 
Halaman sekar alit yang ditujukan pada Gambar 2.3 merupakan halaman dimana user dapat mengetahui pengertian dari sekar alit. Pada halaman ini user dapat berinteraksi dengan sistem ketika ingin mengetahui materi tentang sekar alit dengan memilih salah satu menu yang ada di dalam aplikasi.

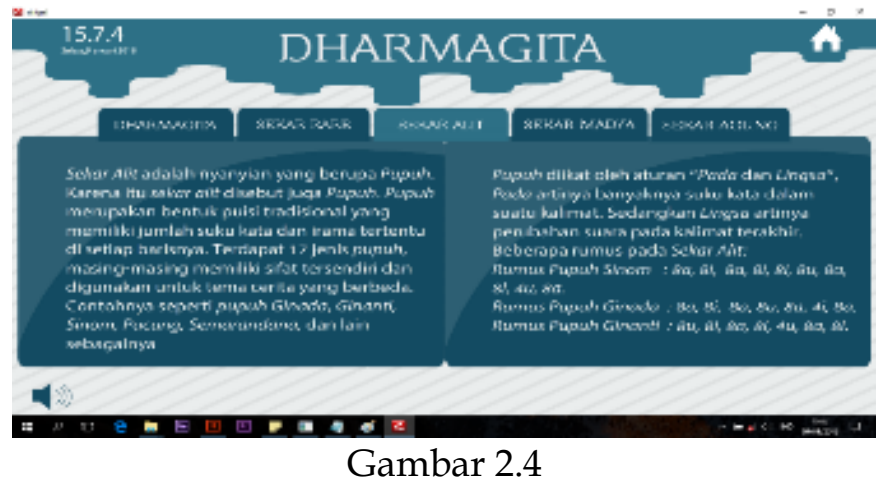

Gambar 2.4 merupakan halaman dimana user dapat mengetahui pengertian dari sekar madya. Pada halaman ini user dapat berinteraksi dengan sistem ketika ingin mengetahui materi tentang sekar madya dengan memilih salah satu menu yang ada di dalam aplikasi.

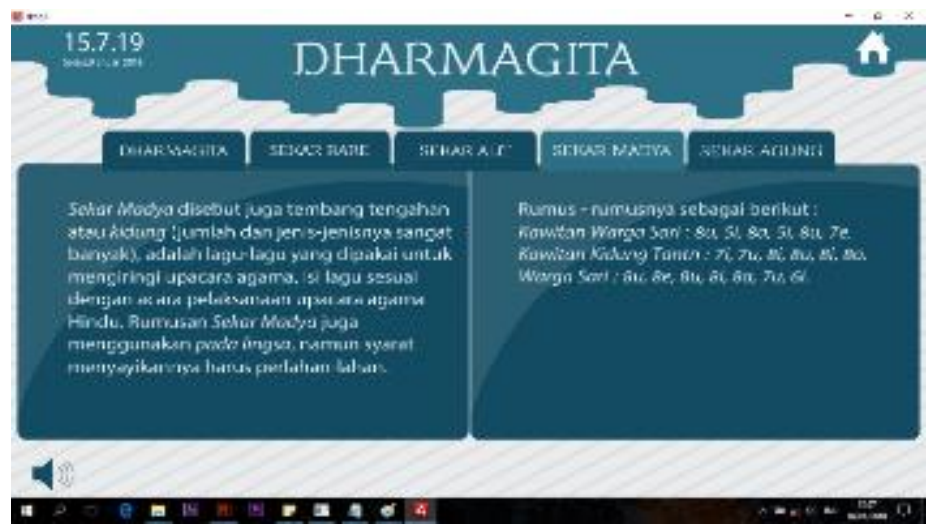

Gambar 2.5

Gambar 2.5 merupakan halaman dimana user dapat mengetahui pengertian dari sekar agung. Pada halaman ini user dapat berinteraksi dengan sistem ketika ingin mengetahui materi tentang sekar agung dengan memilih salah satu menu yang ada di dalam aplikasi. 


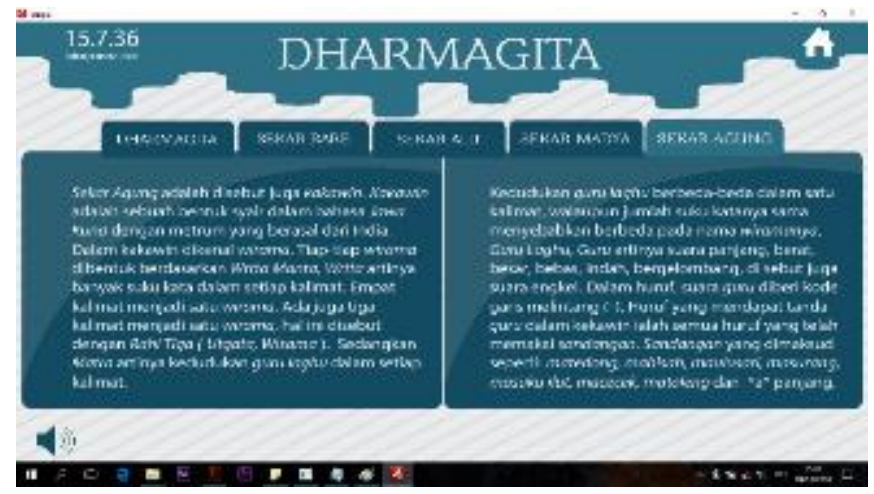

Gambar 2.6

Gambar 2.6 merupakan halaman dimana user dapat memahami pengertian sekar agung. Pada halaman ini user dapat berinteraksi dengan sistem ketika ingin mengetahui materi tentang sekar agung dengan memilih salah satu menu yang ada di dalam aplikasi.

Selanjutnya halaman sloka yang ditujukan pada Gambar 2.7 merupakan halaman dimana user dapat memahami pengertian sloka. Pada halaman ini user dapat berinteraksi dengan sistem ketika ingin mengetahui materi tentang sloka dengan memilih salah satu menu yang ada di dalam aplikasi.

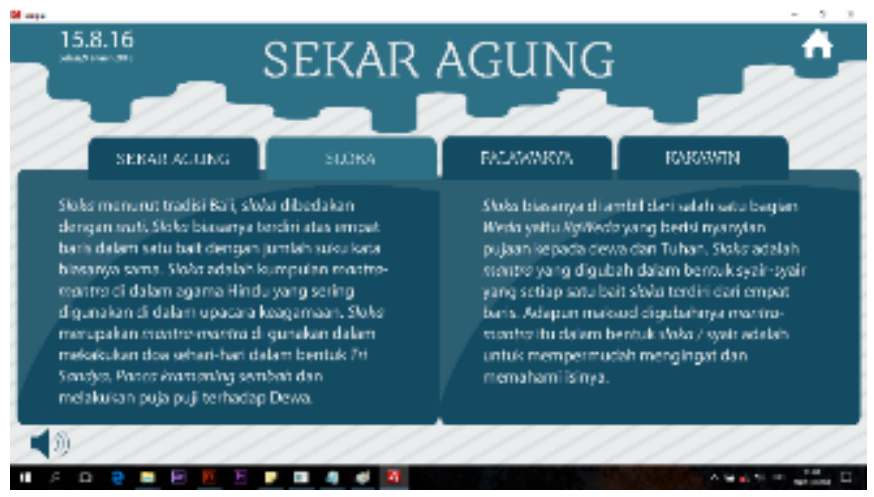

Gambar 2.7

Halaman palawakya yang ditujukan pada Gambar 2.8 merupakan halaman dimana user dapat memahami pengertian palawakya. Pada halaman ini user dapat berinteraksi dengan sistem ketika ingin mengetahui materi tentang palawakya dengan memilih salah satu menu yang ada di dalam aplikasi.

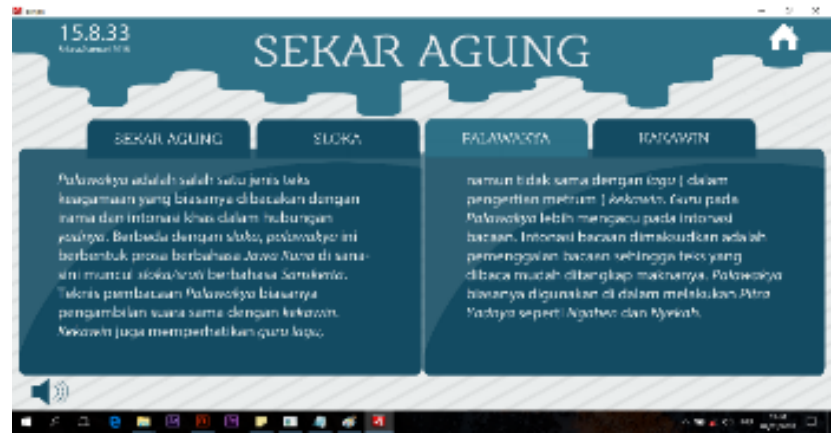

Gambar 2.8

69 | SPHATIKA: Jurnal Teologi Vol. 12 No. 1, Maret 2021 
Halaman kakawin yang ditujukan pada Gambar 2.9 merupakan halaman dimana user dapat memahami pengertian kakawin. Pada halaman ini user dapat berinteraksi dengan sistem ketika ingin mengetahui materi tentang kakawin dengan memilih salah satu menu yang ada di dalam aplikasi.

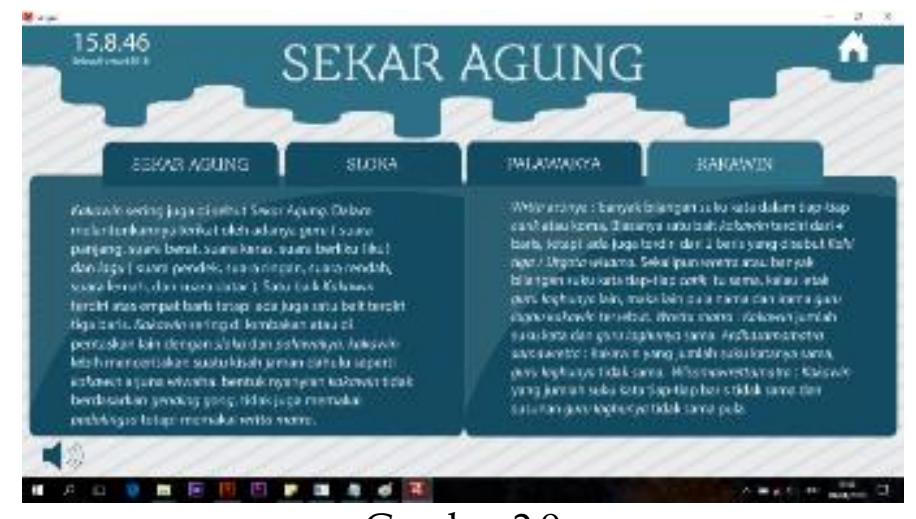

Gambar 2.9

\section{Tampilan Video dan Audio Sekar Agung}

Halaman video \& Audio yang ditujukan pada Gambar 4.1 merupakan halaman dimana user dapat menyaksikan video dan mendengarkan audio sekar agung. Untuk mendengarkan dan menonton video user memilih 3 (tiga) menu yang tersedia.

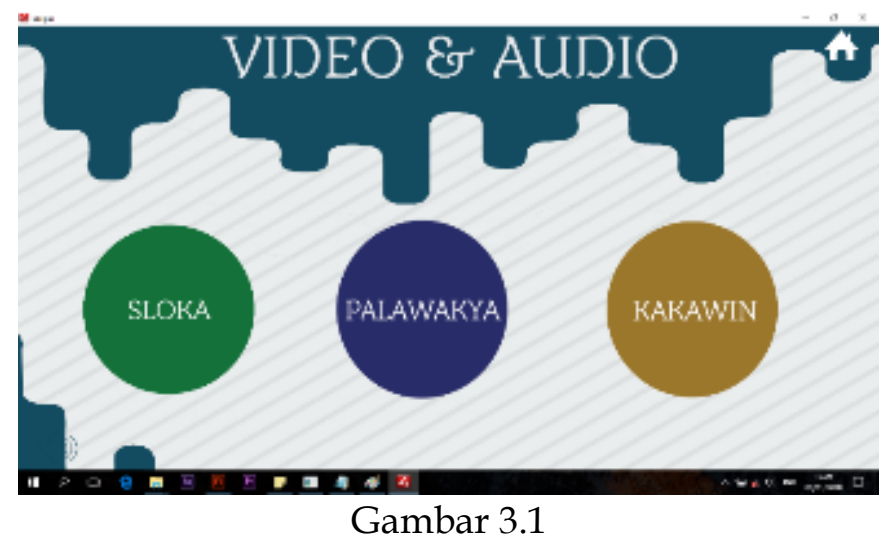

Halaman Sloka yang ditujukan pada Gambar 3.2 dan 3.3 merupakan halaman dimana user dapat mendengarkan audio sloka dan menyaksikan pembacaan sloka. Untuk mendengarkan user memilih 5 (lima) menu audio. 

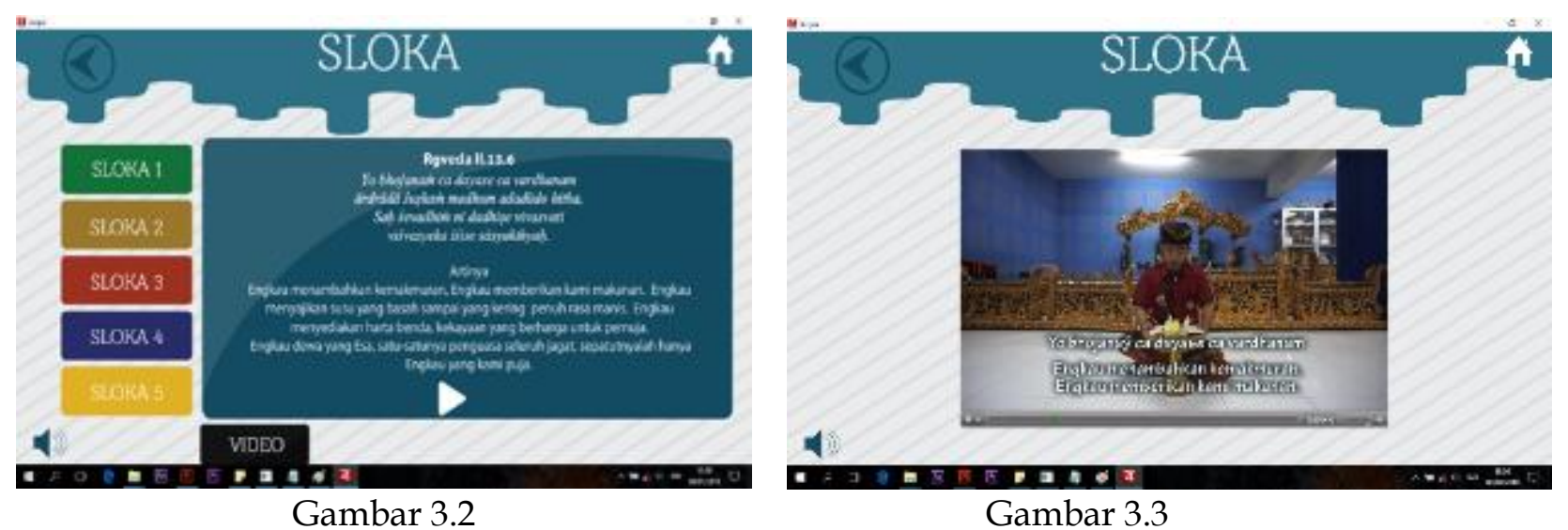

Halaman Palawakya yang ditujukan pada Gambar 3.4 dan 3.5 merupakan halaman dimana user dapat mendengarkan audio Palawakya. Untuk mendengarkan audio user memilih 5 (lima) menu audio.

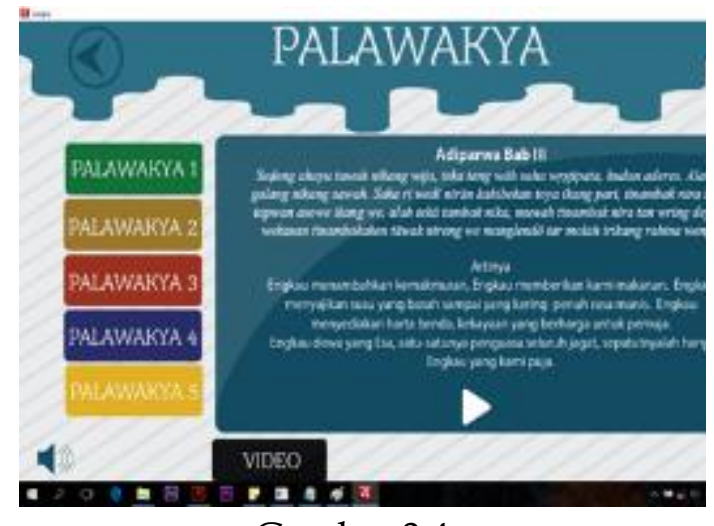

Gambar 3.4

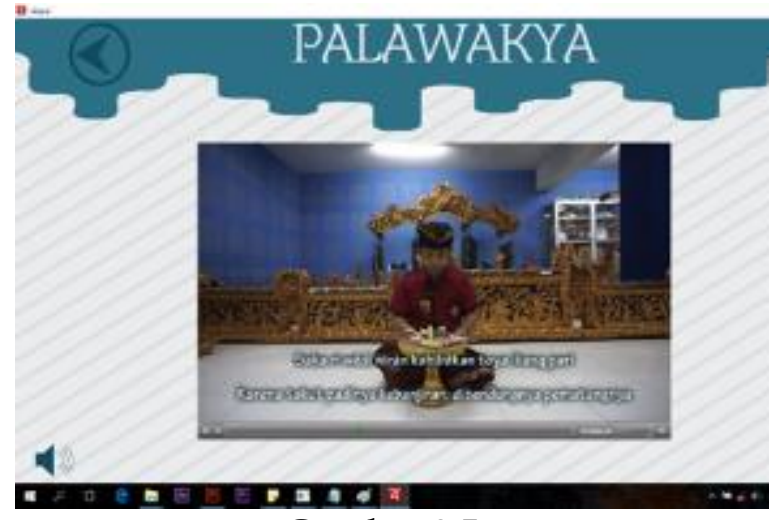

Gambar 3.5

Halaman kakawin yang ditujukan pada Gambar 4.6 dan 4.7 merupakan halaman dimana user dapat mendengarkan audio kakawin. Untuk mendengarkan user memilih 5 (lima) menu audio.
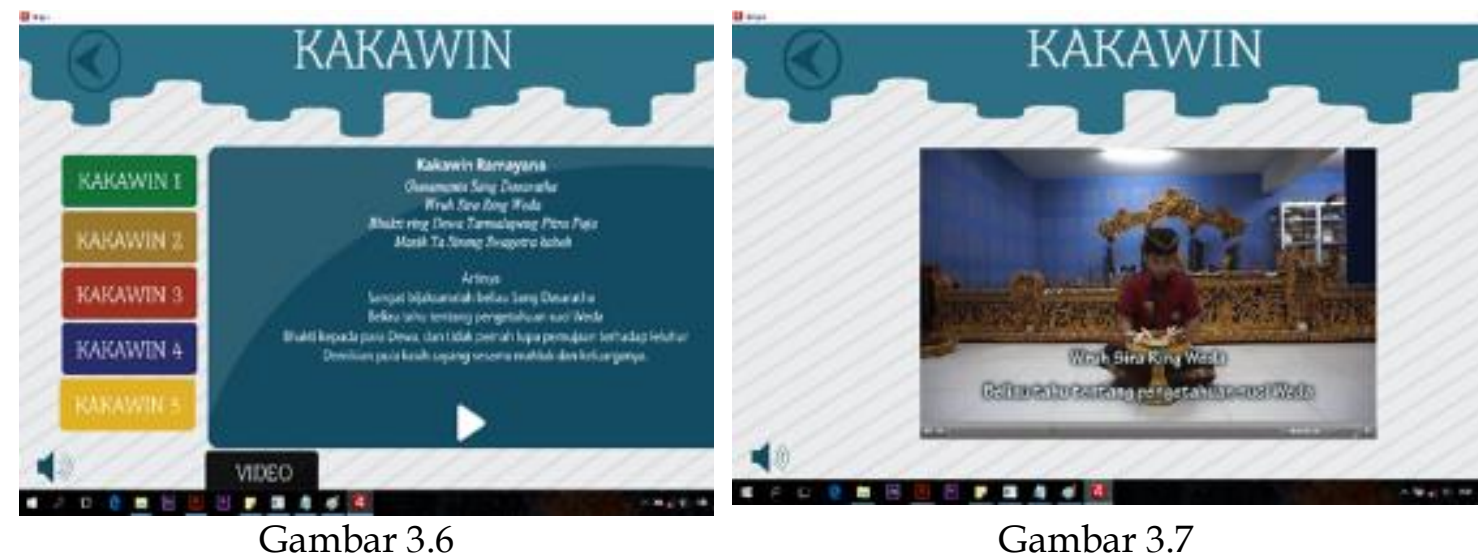

Gambar 3.7 
Halaman kuis yang ditujukan pada Gambar 3.8 dan 3.9 merupakan halaman dimana user mengasah pengetahuan tentang materi sekar agung yang sudah dijelaskan. User dapat memasukkan nama.

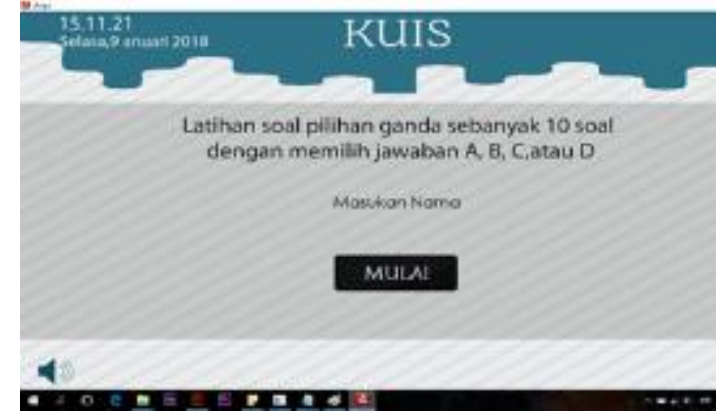

Gambar 3.8

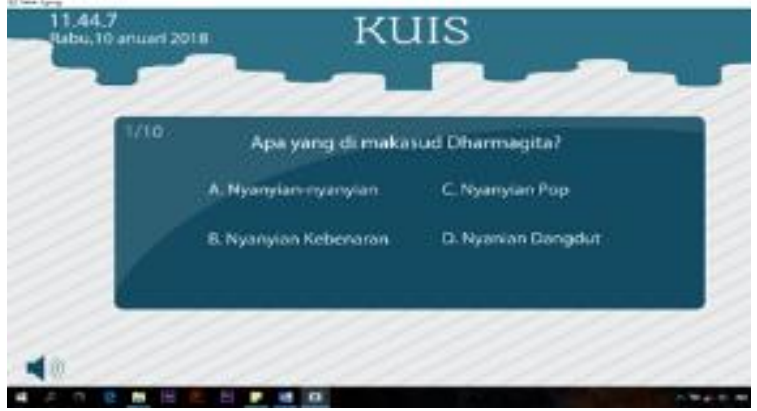

Gambar 3.9

Halaman nilai yang ditujukan pada Gambar 4.10 merupakan halaman nilai dimana user dapat melihat nilai yang diperoleh.

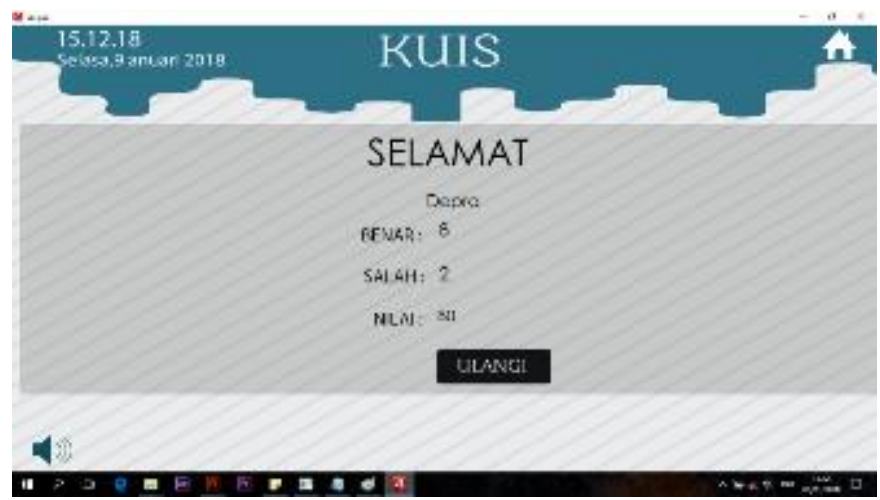

Gambar 3.10

Program pada Gambar 3.10 merupakan kode program yang berfungsi untuk menampilkan nilai yang diperoleh $u$ ser.

\section{Sistem Aplikasi Multimedia Interakif Sekar Agung}

a. Macth between system and the real world (metaphor)

Sistem harus didesain dengan menggunakan bahasa yang mudah dimengerti dan dipahami oleh pengguna awam sekalipun. Pada aplikasi ini, evaluasi metaphor telah baik dilakukan karena telah memberikan struktur yang jelas tentang penjelasan dari dharmagita dan penjelasan bagiannya.

b. User control and freedom (navigation)

Evaluasi ini dimaksud agar pengguna dengan mudah menavigasi suatu sistem. Salah satu contoh bisa di gunakan ketika pengguna ingin berpindah dari satu halaman ke halaman lainnya, dapat menggunakan tombol back. 
c. Consistensy and syandards (consistency)

Evaluasi consistency dimaksudkan agar sistem memiliki standar, seperti penulisan kata, jenis kata huruf, dan standarisasi warna serta desain tataletak yang digunakan sudah cukup baik. Namun dalam informasi dan penjelasan bagian tertentu, penulisan istilah aplikasi ini masih belum standar karena masih menggunkan bahasa asing di dalam penjelasannya.

d. Error prevention (prevention)

Dalam hal ini evaluasi dilakukan dengan mengutakan pencegahan pengguna melakukan kesalahan. Desain antarmuka yang dapat mencegah pengguna melakukan kesalahan. Dalam hal ini di dalam aplikasi ini belum ditemukan peringatan yang mempermudah pengguna.

e. Recognition rather than recall (memory)

Evaluasi yang berkaitan dengan beban kerja (memori) pengguna aplikasi. Pengguna sebaiknya tidak perlu mengingat ketika hendak menjalankan suatu aplikasi. Pada kasus ini penggunaan beban memori yang minimum telah dilakukan salah satunya pada bagian sub menu sloka yang terdapat audio pengguna tinggal menekan tombol play untuk mendengarkan audio dan menekan tombol video untuk melihat video.

f. Flexibility and efficiency (efficiency)

Kecepatan akses dan fleksibelitas serta kecepatan informasi yang diperoleh merupkan hal penting untuk diperhatikan, terutama bagi pengguna baru. Efficiency telah di lakukan dengan baik pada aplikasi ini contohnya pada halaman video sloka, video dapat di akses secara offline tanpa menggunakan koneksi internet.

g. Aesthetic and minimallist design (design)

Hal ini berkaitan dengan estetika pemilihan keselarasan warna pada antarmuka aplikasi, hal yang perlu di perhatikan adalah kontras, pengulangan, keselaran posisi dan cahaya, pada antar muka ini telah didesain dangat baik dengan gaya flat design dan warna berpadu dengan unser hijau, merah, ungu, kuning, dan coklat.

h. Help user recognize diagnose and recover from errors (recovery)

Pesan ketika melakukan kesalahan input data perlu disampaikan dalam bahasa yang jelas. Pada kasus pengguna mengimputkan jawaban pilihan ganda pada 
kuis, sudah di munculkan jawaban yang benar di setiap pertanyaan dan aplikasi juga memunculkan nilai yang didapat oleh pengguna.

i. Help and documentation (help)

Help merupakan bagian yang diperlukan dalam suatu aplikasi, menu help dapat membantu penggunanya ketikan menghadapi kesulitan saat nggunakan sistem, dalam aplikasi ini belum ditemukan adanya menu help untuk memandu pengguna, walupun penggunaan aplikasi ini sudah cukup mudah, jadi perlu ditambahkan fitur help tersebut.

\section{PENUTUP}

Pengenalan Seni Suara Sekar Agung Berbasis Multimedia Interaktif dimana didapatkan kesimpulan sebagai berikut. 1) Telah dihasilkanya aplikasi pengenalan mengenai dharmagita, dan sekar agung berbasis mobile dan dekstop. 2)Telah dihasilkan aplikasi yang interaktif untuk memberikan informai tentang sekar agung. 3) Aplikasi ini digunakan bukan hanya sebagai media pengenalan dan pembelajaran tetapi juga untuk mendokumentasikan warisan budaya dalam bentuk digital. 4)Berdasarkan pengujian sistem menggunakan metode blackbox testing, maka didapatkan hasil dari pengujian tersebut bahwa fungsionalitas sistem yang dibuat sudah sesuai dengan analisis kebutuhan dan desain sistem. 5) Berdasarkan pengujian sistem menggunakan heuristic evaluation, maka dapat disimpulkan telah dihasilkanya aplikasi pengenalan mengenai seni suara sekar agung berbasis multimedia interaktif yang dapat digunakan sebagai media pengenalan dan mendokumentasikan warisan budaya seni suara sekar agung dalam bentuk digital.

\section{DAFTAR PUSTAKA}

Dinas Kebudayaan Provinsi Bali. 2011. Utsawa Dharmagita.Denpasar: Disbud Dix Atan, Filnlay, Janet. 2010. Human Computer Interraction Third Edition. UK:Person.

Suarjana, I Dewa Gede. 2016. Multimedia Interaktif Pengenalan Seni Pencak Silat Bakti Negara Asli Bali. Skripsi. STMIK STIKOM Bali.

Rediastra, I Kadek. 2016. Multimedia Interaktif Pengenalan Tri Hita Karana Dalam Ajaran Agama Hindu, Skripsi. STMIK STIKOM Bali.

Pertama, Pande Putu Gede Putra. 2015. Pengembangan Aplikasi Mobile Pengenalan Aksara Bali Kedalam Huruf Latin Dengan Augmented Reality. Tesis. Yogyakarta:Universitas Atma Jaya

Munir. 2014.Multimedia.Yogyakarta: Alfabeta

MADCOMS,2013.Kupas Tuntas Adobe Flash CS6 .Jakarta:Andi Publiser

MADCOMS,2013.Kupas Tuntas Adobe Photosop CS6.Jakarta: Andi Publiser 
MADCOMS,2015.Kupas Tuntas CoelDraw X7.Jakarta: Andi Publiser Ir. Yuniar Supardi,2007.Flowchart.Jakarta: Dinastindo Ivan Pratama, 2016.Cara Mudah Merancang Storyboard. Jakarta: PT. Taka Publiser M.sidi Mustaqbal, Roeri FajriFirdaus, Hendra Rahmadi, Pengujian Aplikasi Menggunakan Black-box Testing Bondary Value Analysis. Jurnal Ilmiah Teknologi Informasi Terapan.2015;1(3):31-36[15] Rahadi, Dendi Riaonto. Pengukuran Usability Sistem Menggunakan Use Questionare Pada Aplikasi Android. Universitas Bima Darma Palembang 2014. 